\title{
Kinetics and the fracture mechanism in low-cycle fatigue range and static crack resistance of the Mg6Al magnesium alloy after annealing and equal channel angular pressing
}

\author{
G. V. Klevtsov ${ }^{\dagger, 1}$, R.Z. Valiev ${ }^{2}$, N. A. Klevtsova ${ }^{1}$, O. B. Kulyasova ${ }^{2}$, E. D. Merson ${ }^{1}$, \\ M. L. Linderov ${ }^{1}$, A. V. Ganeev ${ }^{2}$ \\ †Klevtsov11948@mail.ru \\ ${ }^{1}$ Togliatti State University, 14 Belorusskaya St., Togliatti, 445020, Russia \\ ${ }^{2}$ SRI Physics of Advanced Materials Ufa State Aviation Technical University, 12 K. Marx St., Ufa, 455000, Russia
}

\begin{abstract}
We studied the static crack resistance, kinetics and fracture mechanism in the low-cycle fatigue range of the Mg6Al magnesium alloy $(5.6 \% \mathrm{Al} ; 0.245 \% \mathrm{Mn} ; 0.047 \% \mathrm{Cl} ; 0.046 \% \mathrm{Ca})$ after homogenization annealing $\left(d_{\mathrm{av}}=85 \mu \mathrm{m}\right)$ and after equal-channel angular pressing (ECAP) $\left(d_{\mathrm{av}}=20 \mu \mathrm{m}\right)$. Fatigue tests of the rectangular samples with a $10 \mathrm{~mm}$ thickness were carried out at a temperature of $20^{\circ} \mathrm{C}$ according to the three-point bending scheme on an Instron 8802 setup at $v=10 \mathrm{~Hz}, R=0.1$ and various load values $\Delta P$. The microfractographic features of the fracture surface were studied in the SIGMA scanning electron microscope (SEM) by "ZEISS» and in a confocal laser scanning microscope (CLSM) Lext OLS4000. It has been shown that after annealing the alloy has extremely low hardness and low tensile mechanical properties. After ECAP, hardness, tensile strength, and yield strength increased by 1.2 -1.3 times, and elongation, despite strain hardening, also increased. It was shown that the static crack resistance $\left(K_{\mathrm{c}}\right)$ of the alloy after ECAP was slightly higher compared to the annealed state. At the same value of $\Delta K$, the propagation rate of a fatigue crack in the ECAPed Mg6Al alloy is lower than in the annealed one, that is favorable in terms of structural strength of the material. The coefficient $n$ in the Paris equation for the annealed alloy is higher than for the ECAPed one. This indicates a lower sensitivity of the alloy after ECAP to cyclic overloads. The microrelief of the fatigue fracture surfaces of the $\mathrm{Mg} 6 \mathrm{Al}$ alloy both after ECAP and in the annealed state is characterized by cleavage-like facets with fluted morphology.
\end{abstract}

Keywords: magnesium alloy, fatigue failure, equal channel angular pressing, structure, fracture mechanism.

УДК: 620.178 .32

\section{Кинетика и механизм разрушения в области малоцикловой усталости и трещиностойкость магниевого сплава Mg6Al} после отжига и равноканального углового прессования

\author{
Клевцов Г. В. ${ }^{\dagger, 1}$, Валиев Р. З. ${ }^{2}$, Клевцова Н. А. ${ }^{1}$, Кулясова О. Б. ${ }^{2}$, Мерсон Е. Д. ${ }^{1}$, \\ Линдеров М. Л. ${ }^{1}$, Ганеев А. В. ${ }^{2}$ \\ ${ }^{1}$ Тольяттинский государственный университет, ул. Белорусская, 14, Тольятти, 445020, Россия \\ ${ }^{2}$ НИИ Физики перспективных материалов УГАТУ, ул. К. Маркса, 12, Уфа, 455000, Россия
}

Исследовали статическую трещиностойкость, кинетику и механизм разрушения в области малоцикловой усталости магниевого сплава $\mathrm{Mg} 6 \mathrm{Al}$ (5.6\% Al; 0.245\% Mn; 0.047\% Cl; 0.046\% Са) после гомогенизационного отжига $\left(d_{\text {ср }}=85\right.$ мкм $)$ и после равноканального углового прессования (РКУП) $\left(d_{c p}=20\right.$ мкм). Усталостные испытания прямоугольных образцов толщиной 10 мм проводили при температуре $20^{\circ} \mathrm{C}$ по схеме трехточечного изгиба на установке Instron 8802 при $v=10$ Гц, $R=0.1$ и различных значениях нагрузки $Р$. Микрофрактографические особенности строения изломов исследовали в растровом электронном микроскопе (РЭM) SIGMA фирмы «ZEISS» и в конфокальном 
лазерном сканирующим микроскопе (КЛСM) Lext OLS4000. Показано, что после отжига сплав имеет крайне низкую твердость и низкие механические свойства при растяжении. После РКУП твердость, предел прочности и предел текучести возрастают в 1.2-1.3 раза, а относительное удлинение, несмотря на деформационное упрочнение, даже увеличилось. Показано, что статическая трещиностойкость $\left(K_{\mathrm{C}}\right)$ сплава после РКУП, незначительно выше по сравнению с отожженным состоянием. При одном и том же значении коэффициента $\Delta K$ скорость распространения усталостной трещины в сплаве Mg6Al после РКУП ниже, чем в отожженном сплаве, что благоприятно с позиции конструктивной прочности материала. Коэффициент $n$ в уравнении Пэриса для сплава после отожженного состояния выше, чем для сплава после РКУП. Это свидетельствует о меньшей чувствительности данного сплава после РКУП к циклическим перегрузкам. Микрорельеф усталостных изломов сплава Mg6Al как после РКУП, так и в отожженном состоянии характеризуется сколоподобными фасетками с трубчатой морфологией.

Ключевые слова: магниевый сплав, усталостное разрушение, равноканальное угловое прессование, структура, механизм разрушения.

\section{1. Введение}

Конструктивная прочность металлических материалов включает в себя целый комплекс прочностных и пластических свойств, важнейшим из которых является трещиностойкость иусталостная прочность $[1,2]$. Весьма перспективным способом повышения прочностных свойств материалов признано использование различных схем интенсивной пластической деформации (ИПД) [3]. В работах [4-16] показано, что при помощи ИПД в сталях, титановых, алюминиевых и медных сплавах можно создать ультрамелкозернистую (УМЗ) структуру, которая обеспечивает повышение предела усталости данных материалов. В то же время, усталостная прочность в области малоцикловой усталости снижается или повышается незначительно. Эстрин и Виноградов [5,12] показали, что материалы, подвергнутые равноканальному угловому прессованию (РКУП), как правило, имеют более низкие пороговые значения коэффициентов $\Delta K$ и более высокую скорость распространения трещины в стационарном режиме, чем те же материалы в крупнозернистом (КЗ) состоянии. Низкую прочность УМЗ материалов в области малоцикловой усталости авторы $[5,12]$ связывают с меньшей извилистостью распространяющейся трещины, и с относительно развитой циклической пластической деформацией у вершины трещины и рядом других факторов [17].

Целью настоящей работы является повышение усталостной прочности и трещиностойкости магниевого сплава Mg6Al, путем использования РКУП, а также исследование влияния РКУП на механизм разрушения данного сплава.

\section{2. Материал и методики исследования}

Магниевый сплав $\mathrm{Mg} 6 \mathrm{Al}(5.6 \% \mathrm{Al} ; 0.245 \% \mathrm{Mn} ; 0.047 \% \mathrm{Cl}$; $0.046 \% \mathrm{Ca})$ исследовали после гомогенизационного отжига и после РКУП. Отжиг сплава в литом состоянии проводили при температуре $430^{\circ} \mathrm{C}$ в течение 24 часов в среде аргона с последующей закалкой в воде. После вышеуказанной термической обработки партию сплава подвергали РКУП при температуре $400^{\circ} \mathrm{C}(n=4$, маршрут $\mathrm{Bc}, \varphi=120^{\circ}$ ) [3] с промежуточным нагревом до температуры $400^{\circ} \mathrm{C}$ в течение 15 минут перед каждым проходом.
Исследование микроструктуры сплава проводили на металлографическом микроскопе Olimpus GX-51. Испытание сплава на твердость проводили на твердомере ТН 300. Статическое растяжение цилиндрических образцов диаметром 3 мм при температуре 20 и $-196^{\circ} \mathrm{C}$ проводили на универсальной испытательной машине Н50КТ. Испытание на статическую трещиностойкость $\left(K_{1 \mathrm{C}}\right)$ проводили на прямоугольных образцах толщиной 10 мм по схеме трехточечного изгиба согласно ГОСТ $25.506-85$ в среде жидкого азота $\left(-196^{\circ} \mathrm{C}\right)$. Усталостные испытания призматических образцов толщиной 10 мм проводили при температуре $20^{\circ} \mathrm{C}$ по схеме трехточечного изгиба на установке Instron 8802 при частоте нагружения $v=10$ Гц и коэффициенте асимметрии цикла $R=0.1$. Образцы испытывали при нагрузках 800 и 1000 Н. Микрофрактографические особенности строения изломов исследовали в растровом электронном микроскопе (PЭM) SIGMA (ZEISS) и в конфокальном лазерном сканирующим микроскопе (КЛСM) Lext OLS4000 (Olympus).

\section{3. Результаты исследования и их обсуждение}

Исследование микроструктуры магниевого сплава Mg6Al показало, что средний размер зерен в гомогенизированном состоянии равен 85 мкм; средний размер зерен в сплаве после РКУП - 20 мкм. В гомогенизированном состоянии видна вторая фаза $\left(\mathrm{Mg}_{17} \mathrm{Al}_{12}\right)$ по границам зерен (Рис. 1a). После РКУП данной фазы стало меньше (Рис. $1 \mathrm{~b})$, что говорит о ее частичном растворении в процессе горячей деформации $\left(0.73 T_{\text {пл }}\right)$.

После отжига сплав имеет крайне низкую твердость и низкие механические свойства при растяжении (Табл. 1). После РКУП твердость, предел прочности и предел текучести возрастают в $1.2-1.3$ раза. Относительное удлинение сплава, несмотря на деформационное упрочнение, также возрастают в 1.2 раза.

Статическая трещиностойкость сплава после РКУП, незначительно выше по сравнению с отожженным состоянием (Табл. 2). Однако, согласно критерию $t /\left(K_{1 \mathrm{C}} / \sigma_{0.2}\right)^{2}$, при данных размерах образцов и условиях испытания плоская деформация (ПД) не была достигнута, хотя критерий $\varphi_{c}$ удовлетворяет условию ПД.

Механизм статического разрушения КЗ сплава смешанный: хрупкое расслоение чередуется с вязкими ям- 




a

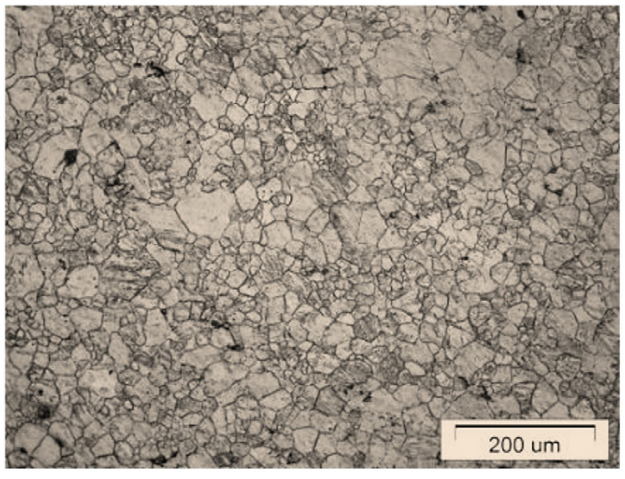

$\mathrm{b}$

Рис. 1. Микроструктура магниевого сплава Mg6Al после гомогенизации (a) и после РКУП (b).

Fig. 1. The microstructure of the magnesium alloy $\mathrm{Mg} 6 \mathrm{Al}$ after homogenization (a) and after ECAP (b).

ками. Микрорельеф УМЗ сплава также смешанный: расслоение по плоскостям скольжения и гребни чередуются с ямками; имеются вторичные трещины.

Анализ прямолинейного участка кинетических диаграмм усталостного разрушения магниевого сплава Mg6Al показал, что при одном и том же значении коэффициента $\Delta K$ скорость распространения усталостной трещины в сплаве после РКУП ниже, чем в сплаве после отжига (Рис. 2), что благоприятно с точки зрения конструктивной прочности материала. Прямолинейный участок кинетических диаграмм усталостного разрушения сплава описывается уравнением Пэриса [18] (Табл. 3). Из Табл. 3 видно, что коэффициент $n$ в уравнении Пэриса для сплава после РКУП ниже, чем в сплаве после отжига. Следовательно, сплав после РКУП менее чувствителен к циклическим перегрузкам $[19,20]$.

На поверхности всех усталостных изломов сплава $\mathrm{Mg6Al}$ видны две зоны: зона усталостного развития трещины $1_{f}$ и зона долома [20]. В изломах сплава после отжига зона $l_{\mathrm{f}}$ имеет кристаллическое строение, а зона долома - большую шероховатость. В изломах сплава после РКУП зона $l_{f}$ гладкая, а зона долома имеет волокнистое строение.

Начиная от надреза и далее в пределах зоны $l_{f}$ (Рис. $3 \mathrm{a}, \mathrm{b}, \mathrm{d}, \mathrm{e}$ ) поверхность усталостных изломов отожженного сплава Mg6Al состоит из транскристаллитных сколоподобных фасеток, размер которых, примерно, совпадает с размером зерна сплава. Морфология фасеток представлена эквидистантными, параллельными трубками, ориентация которых в пределах фасетки одинакова. Несмотря на очевидную кристаллографическую ориентацию и внешнее сходство с фасетками скола, образование трубчатого микрорельефа данных фасеток, согласно литературным данным, может быть результатом разновидности вязкого разрушения. Образование такого рельефа во многих ГПУ металлах объясняют формированием вытянутых пор в виде трубок на пересечении полос скольжения и последующим разрывом перемычек между ними $[21,22]$. В частности, трубчатый излом наблюдали при коррозионной усталости в ГПУ металлах, например, в титановых [21] и циркониевых сплавах [23], а также при коррозионном растрескивании под напряжением магния и его сплавов [22,24]. При большом увеличении видно

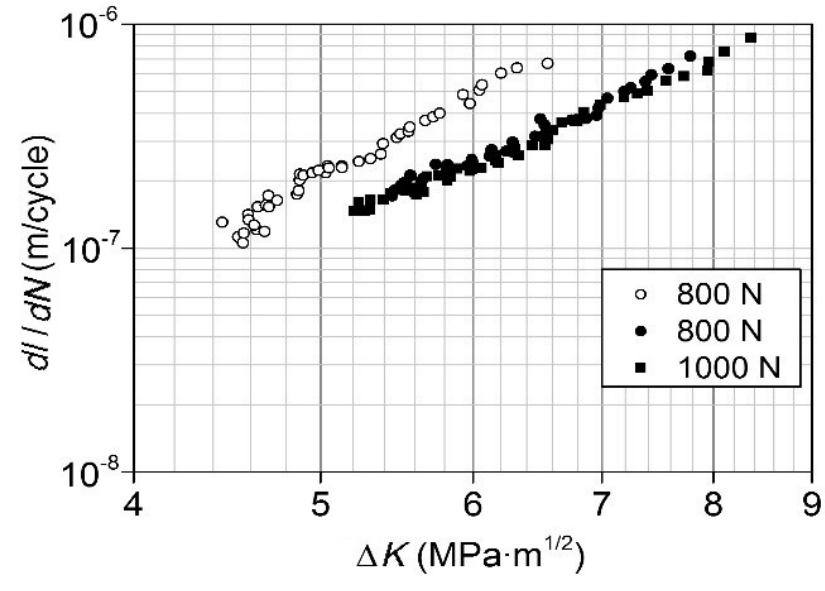

Рис. 2. Прямолинейный участок кинетических диаграмм усталостного разрушения сплава Mg6Al после отжига (светлые точки) и после РКУП (темные точки).

Fig. 2. A straight-line section of the kinetic diagrams of the fatigue fracture of the Mg6Al magnesium alloy after annealing (white dots) and after ECAP (black dots).

(Рис. 3е), что на границах зерен встречаются участки с микрорельефом, близким к ямочному. Вблизи зоны долома микрорельеф приобретает смешанный характер: помимо трубчатого рельефа имеют место вторичные вязкие межзеренные трещины. В зоне долома микрорельеф также смешанный с преобладанием ямочного.

Микрорельеф усталостных изломов сплава после РКУП также характеризуется трубчатой морфологией. Однако трубки фрагментированы уже в очаге разрушения (Рис. $4 \mathrm{a}, \mathrm{d}$ ). В средней части излома такой микрорельеф сохраняется (Рис. 4 b). При большом увеличении видны вязкие гребни, усталостные бороздки и вторичные трещины (Рис. 4 е). Вблизи долома процент ямочной составляющей увеличивается; микрорельеф становится более дисперсный (Рис. 4c). В основном это вязкие гребни отрыва, вязкие бороздки; видны поры и включения второй фазы (Рис. 4f). Микрорельеф зоны долома гладкие вытянутые ямки.

Таким образом, РКУП по вышеуказанным режимам, измельчая зерно и увеличивая плотность дислокаций в сплаве Mg6Al, благоприятно влияет на статическую 
Табл. 1. Средние значения размера зерна $\left(d_{\mathrm{cp}}\right)$, твердости $(\mathrm{HB})$, предела прочности $\left(\sigma_{\mathrm{B}}\right)$, предела текучести $\left(\sigma_{0.2}\right)$ и относительного удлинения сплава $\mathrm{Mg} 6 \mathrm{Al}$ при $20^{\circ} \mathrm{C} /-196^{\circ} \mathrm{C}$.

Table 1. The average value of grain size $\left(d_{\text {av }}\right)$, hardness $(\mathrm{HB})$, tensile strength $\left(\sigma_{\mathrm{TS}}\right)$, yield strength $\left(\sigma_{0.2}\right)$ and elongation of $\mathrm{Mg} 6 \mathrm{Al}$ alloy at $20^{\circ} \mathrm{C} /-196^{\circ} \mathrm{C}$.

\begin{tabular}{|c|c|c|c|c|c|}
\hline $\begin{array}{c}\text { Состояние } \\
\text { State }\end{array}$ & $\begin{array}{c}d_{\mathrm{cp}}, \mathrm{M \kappa м} \\
d_{\mathrm{av}}, \mu \mathrm{m}\end{array}$ & $\mathrm{HB}$ & $\begin{array}{c}\sigma_{\mathrm{s}}, \mathrm{M \Pi а} \\
\sigma_{\mathrm{TS}}, \mathrm{MPa}\end{array}$ & $\begin{array}{c}\sigma_{0.2}, \mathrm{M \Pi а} \\
\sigma_{0.2}, \mathrm{MPa}\end{array}$ & $\delta, \%$ \\
\hline $\begin{array}{c}\text { После отжига } \\
\text { After annealing }\end{array}$ & 85 & 48 & $230 \pm 10 / 270 \pm 5.0$ & $75 \pm 5.0 / 130 \pm 5.0$ & $8.5 \pm 1.5 / 8.0 \pm 1.5$ \\
\hline $\begin{array}{c}\text { После РКУП } \\
\text { After ЕСАР }\end{array}$ & 20 & 60 & $260 \pm 15 / 315 \pm 5.0$ & $100 \pm 10 / 140 \pm 15$ & $10 \pm 1.0 / 9.0 \pm 1.0$ \\
\hline
\end{tabular}

Табл. 2. Средние значения статической трещиностойкости, максимальной нагрузки и критериев реализации условий ПД сплава $\mathrm{Mg} 6 \mathrm{Al}$ в различном состоянии по ГОСТ 25.506-85.

Table 2. The average values of static crack resistance, maximum load and criteria for the implementation of the PD conditions of the Mg6Al alloy in a different state according to GOST 25.506-85.

\begin{tabular}{|c|c|c|c|c|c|}
\hline $\begin{array}{c}\text { Состояние } \\
\text { State }\end{array}$ & $\begin{array}{c}K_{\mathrm{C}}, \mathrm{MПa} \sqrt{\mathrm{M}}_{\mathrm{C}} \\
K_{\mathrm{C}}, \mathrm{MPa} \sqrt{\mathrm{M}}\end{array}$ & $P, \mathrm{H}$ & $\begin{array}{c}t /\left(K_{\mathrm{CC}} / \sigma_{0.2}\right)^{2} \\
t /\left(K_{1 \mathrm{C}} / \sigma_{0.2}\right)^{2}\end{array}$ & $P_{\max } / P_{\mathrm{Q}}$ & $\varphi_{\mathrm{c}} \%$ \\
\hline $\begin{array}{c}\text { После отжига } \\
\text { After annealing }\end{array}$ & $14.0 \pm 1.2$ & $1475 \pm 102$ & 0.9 & 1.25 & 0 \\
\hline $\begin{array}{c}\text { После РКУП } \\
\text { After ЕСАР }\end{array}$ & $16.5 \pm 0.7$ & $1660 \pm 60$ & 0.7 & 1.13 & 1.1 \\
\hline
\end{tabular}

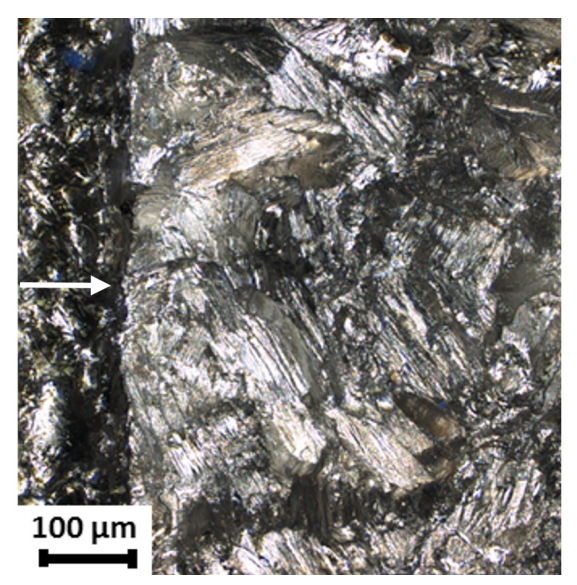

a

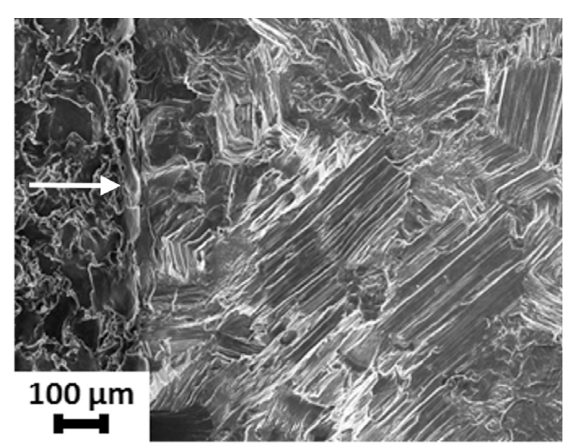

d

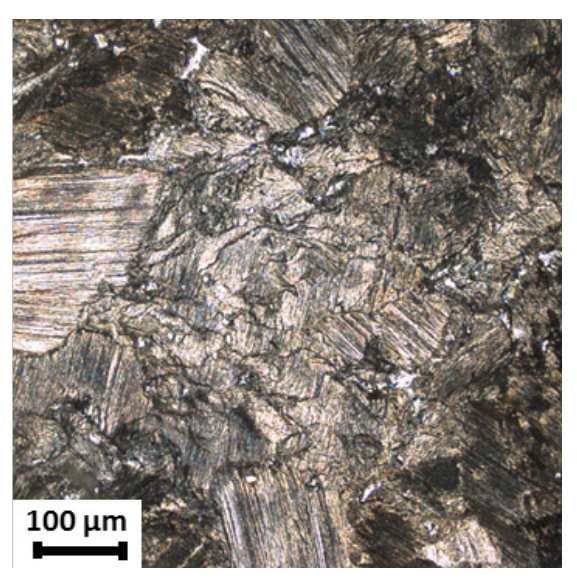

$\mathrm{b}$

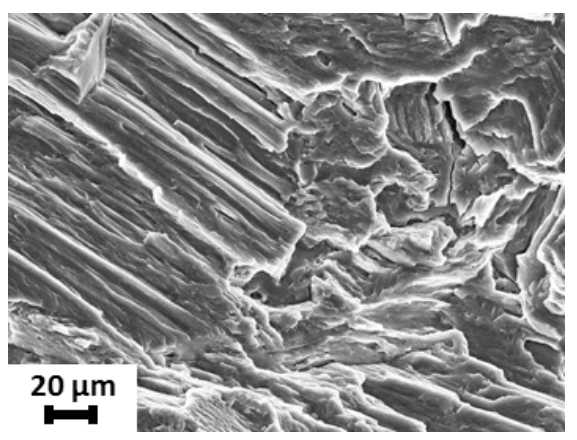

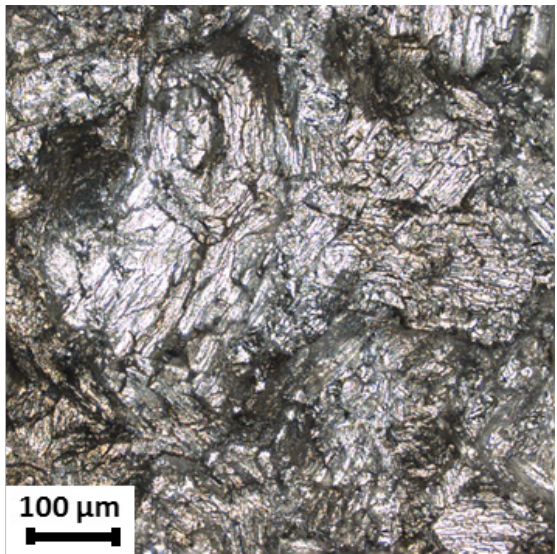

c

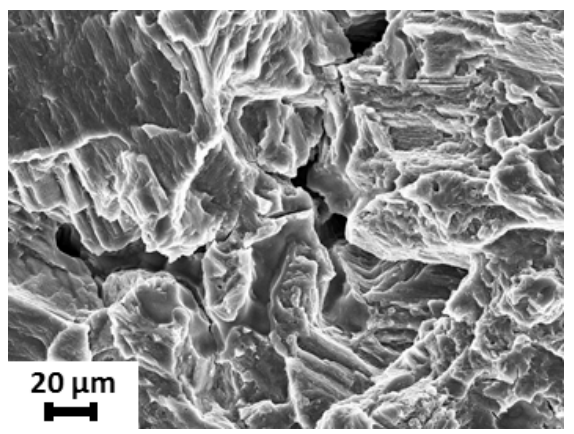

f

Pис. 3. (Color online) Микрорельеф усталостного излома магниевого сплава Mg6Al в отожжённом состоянии в очаге разрушения (очаг отмечен стрелкой) (a,d); в средней части излома при $l=4$ мм (b, e) и вблизи зоны долома (c, f). КЛСМ (a-c), РЭМ (d-f).

Fig. 3. (Color online) The fatigue fracture microrelief of the $\mathrm{Mg} 6 \mathrm{Al}$ magnesium alloy in the annealed state in the fracture initiation region (the origin is indicated by arrows) (a, d); in the middle part of the fracture at $l=4 \mathrm{~mm}(\mathrm{~b}, \mathrm{e})$ and near the final fracture zone (c, f). CLSM (a-s), SEM (d-f). 


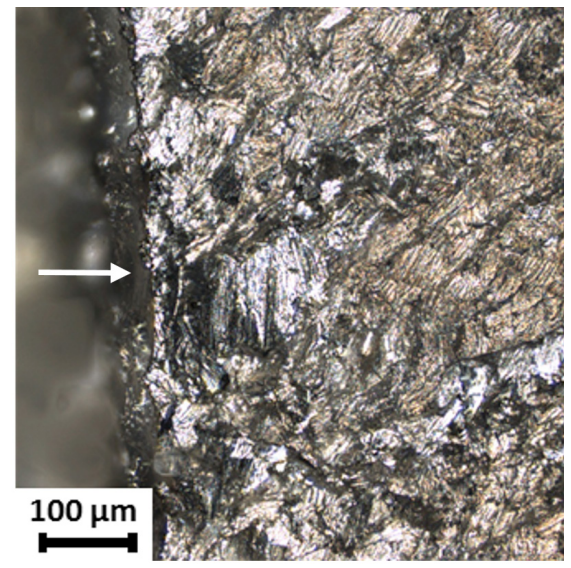

a

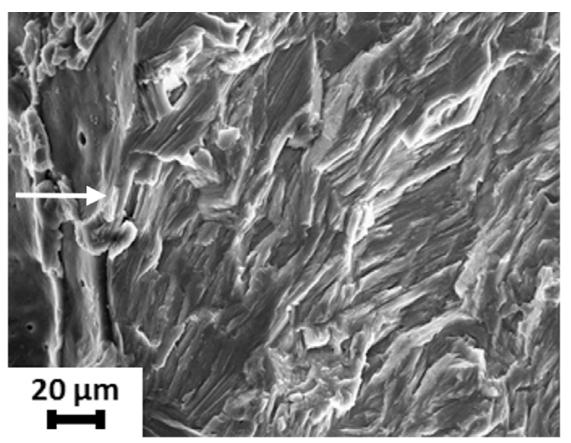

d

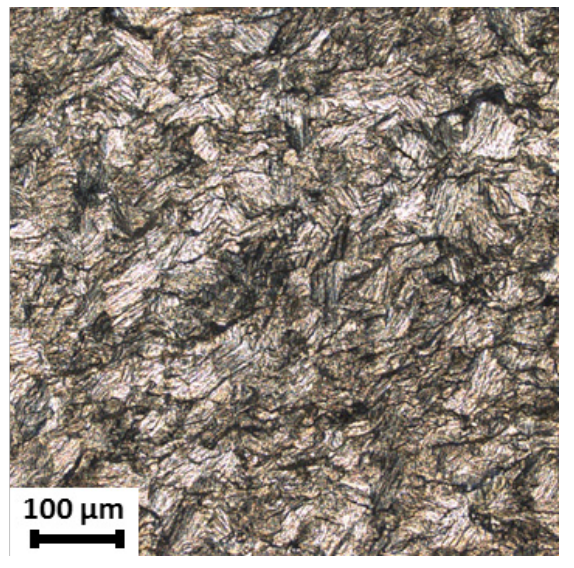

b

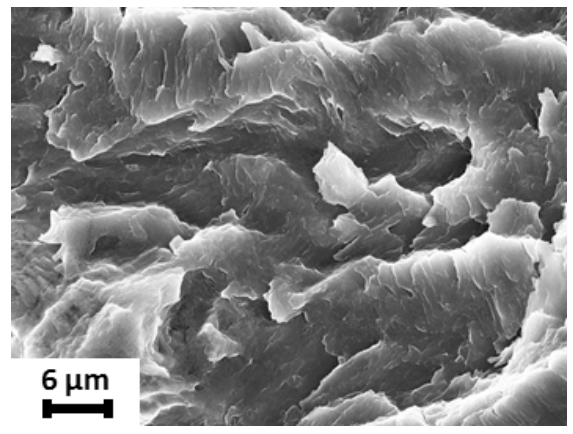

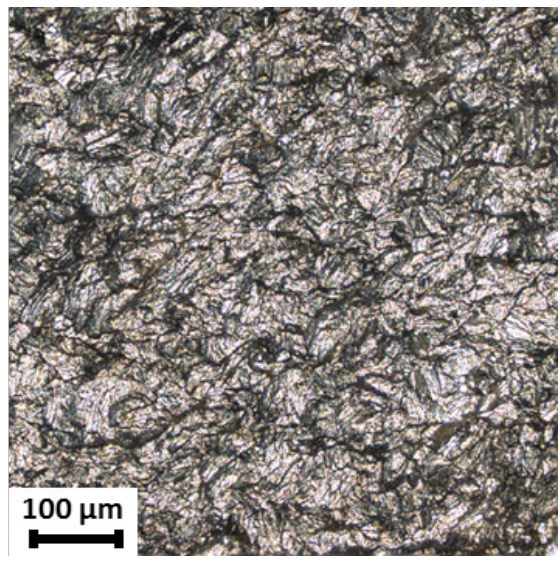

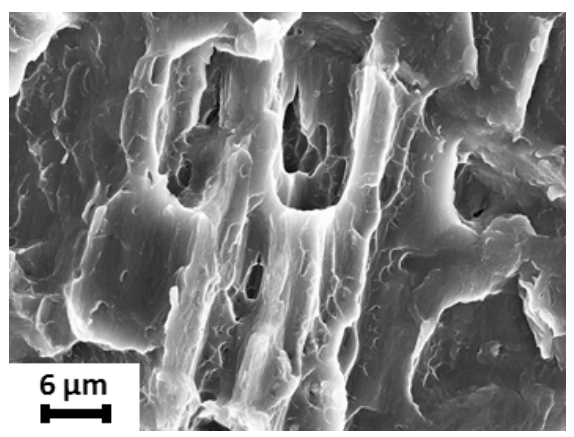

$\mathrm{f}$

Pис. 4. (Color online) Микрорельеф усталостного излома магниевого сплава Mg6Al после РКУП в очаге разрушения (очаг отмечен стрелкой) (a); в средней части излома при $l=5$ мм (b, е) и вблизи зоны долома (c, f). КЛСМ (a-c), РЭМ (d-f).

Fig. 4. (Color online) The fatigue fracture microrelief of the Mg6Al magnesium alloy after ECAP in the fracture origin (the origin is indicated by arrows) (a); in the middle part of the fracture at $l=4 \mathrm{~mm}(\mathrm{~b}, \mathrm{e})$ and near the final fracture zone (c, f). CLSM (a-s), SEM (d-f).

табл. 3. Уравнения Пэриса, описывающие прямолинейный участок кинетических диаграмм усталостного разрушения сплава Mg6Al после различных видов обработки.

Table 3. Paris equations describing the rectilinear region of the kinetic diagrams of fatigue fracture of the $\mathrm{Mg} 6 \mathrm{Al}$ alloy after various types of processing.

\begin{tabular}{|c|c|}
\hline $\begin{array}{c}\text { После отжига } \\
\text { After annealing }\end{array}$ & $\begin{array}{c}\text { После РКУП } \\
\text { After ЕСАР }\end{array}$ \\
\hline$\frac{d l}{d N}=8.9 \cdot 10^{-11}(\Delta K)^{4.8}$ & $\frac{d l}{d N}=3.6 \cdot 10^{-10}(\Delta K)^{3.7}$ \\
\hline
\end{tabular}

трещиностойкость и усталостную прочность сплава, снижая скорость распространения усталостной трещины и уменьшая чувствительность сплава к циклическим перегрузкам. Доминирующим микрорельефом усталостных изломов, независимо от состояния сплава, являются транскристаллитные фасетки с трубчатой морфологией.

\section{4. Выводы}

1. Обработка отожженного магниевого сплава $\mathrm{Mg} 6 \mathrm{Al}$ при помощи РКУП по предложенному режиму приводит к уменьшению размера зерна с 85 до 20 мкм. Твердость и прочностные свойства при растяжении, а также пластичность при этом увеличиваются в $1.2-1.3$ раза.
2. РКУП незначительно повышает статическую трещиностойкость $\left(K_{\mathrm{C}}\right)$ сплава по сравнению с отожжённым состоянием (с $14.0 \pm 1.2$ до $16.5 \pm 0.7 \mathrm{MПа} \sqrt{M}_{\mathrm{M}}$ ).

3. При одном и том же значении коэффициента $\Delta K$ скорость распространения усталостной трещины в сплаве после РКУП ниже, чем в отожженном сплаве, что благоприятно с точки зрения конструктивной прочности материала.

4. Коэффициент $n$ в уравнении Пэриса для сплава $\mathrm{Mg} 6 \mathrm{Al}$ в отожженном состоянии равен 4.8, а после РКУП - 3.8, что свидетельствует о меньшей чувствительности данного сплава после РКУП к циклическим перегрузкам.

5. Доминирующий механизм роста усталостной трещины в сплаве Mg6Al как после РКУП, так и в отожженном состоянии характеризуется формированием, кристаллографически ориентированных транскристаллитных фасеток с трубчатой морфологией.

Благодарности/Acknowledgements. Работа выполнена при бинансовой поддержке РФФИ (проект 18-08-00340_а). Авторы благодарят сотрудника ТГУ И.Н. Пигалеву за помощь в проведении экспериментальной части paбombl. / This work was supported by the Russian Foundation for Basic Research (RFBR) [grant \#18-08-00340_a]. The authors thank the TSU employee I.N. Pigaleva for help in carrying out the experimental part of the work. 


\section{Литература/References}

1. M. A. Shtremel. Fracture. In 2 book. Book 1 . The fracture of the material. Moscow: Publishing House MISiS House (2014) 670 p. (in Russian) [M. А. Штремель. Разрушение. В 2 кн. Кн. 1. Разрушение материала. Москва, Изд. Дом МИСиС (2014) 670 с.]

2. A.J. McEvily. Metal Failures: Mechanisms, Analysis, Prevention. Wiley \& Sons (2002) $324 \mathrm{p}$.

3. R.Z. Valiev, A.P. Zhilyaev, T.G. Langdon. Bulk Nanostructured Materials: Fundamentals and Applications. TMS, WILEY (2014) 440 p. Crossref

4. C.S. Chung, J.K. Kim, H.K. Kim, W.J. Kim. Mater. Sci. Eng. A. 337, 39 (2002). Crossref

5. A. Vinogradov, S. Nagasaki, V. Patland, K. Kitagawa, M. Kawazoe. Nanostruct. Mater. 11, 925 (1999). Crossref

6. P. S. Pao, H. N. Jones, S. F. Cheng, C. R. Feng. Int. Jour. Fat. 27, 1164 (2004). Crossref

7. P. Cavaliere. Int. Jour. Fat. 31, 1476 (1999). Crossref

8. L. Collini. Eng. Frac. Mech. 77. 1001 (2010). Crossref

9. H.K. Kim, M.I. Choi, C.S. Chung, D. H. Shin. Mater. Sci. Eng. A. 340, 243 (2003). Crossref

10. T. Hanlon, E. D. Tabachnikova, S. Suresh. Int. Jour. Fat. 27, 1147 (2005). Crossref

11. L.W. Meyer, K. Sommer, T. Halle, M. Hockauf. Jour. Mater. Sci. 43, 7426 (2008). Crossref

12. Y. Estrin, A. Vinogradov. Int. Jour. of Fatigue. 32, 898 (2010). . Crossref

13. H. Mughrabi, H. W. Hoppel, M. Kautz. Scripta Materialia. 51, 807 (2004). . Crossref
14. L. W. Meyer, K. Sommer, T. Halle, M Hockauf. Materials Science Forum. 584- 586, 815 (2008). Crossref

15. I.P. Semenova, G. Kh. Salimgareeva, V.V. Latysh, T. Lowe, R. Z. Valiev. Mater. Sci. Eng. A. 503, 92 (2009). Crossref

16. L.R. Saitova, H.W. Hoeppel, M. Goeken, A. R. Kilmametov, I. P. Semenova, R.Z. Valiev. Mater. Sci. Forum. 584-586, 827 (2008). Crossref

17. A. Vinogradov. J. Mater. Sci. 42, 1797 (2007). Crossref

18. P. A. Paris, F. A. Erdogan. Trans. ASME, S. D. 4, 582 (1963).

19. J. R. Rice. ASTM. Special Technical Publication. 415, 247 (1966).

20. G. V. Klevtsov, L. R. Botvina, N. A. Klevtsova, L. V. Limar. Fractodiagnosis of the fracture of metallic materials and structures. Moscow, MISiS (2007) 264 p. (in Russian) [Г. В. Клевцов, Л. Р. Ботвина, Н. А. Клевцова, Л.В. Лимарь. Фрактодиагностика разрушения металлических материалов и конструкций. Москва, МИСиС (2007) 264 с.]

21. D. A. Meyn, E. J. Brooks. Microstructural Origin of Flutes and Their Use in Distinguishing Striationless Fatigue Cleavage from Stress-Corrosion Cracking in Titanium Alloys. In: Fractography Mater. Sci. ASTMSTP 733. (Ed. by L.N. Gilbertson, R.D. Zipp). American Society for Testing and Materials (1981) pp. 5-31.

22. S. P. Lynch, P. Trevena. Corrosion. 44, 113 (1988). Crossref

23. T. Motooka, K. Kiuchi. Corrosion. 58, 535 (2002). Crossref

24. E. Merson, V. Poluyanov, P. Myagkikh, D. Merson, A. Vinogradov. Mater. Sci. Eng. A. 772, 138744 (2020). Crossref 